\title{
Comparative experimental and numerical analysis of bending behaviour of dry and low viscous infiltrated woven fabrics
}

\author{
Christian Poppe*, Tobias Rosenkranz, Dominik Dörr, Luise Kärger \\ Karlsruhe Institute of Technology, Institute for Vehicle System Technology, Chair of Light-Weight Technology, Rintheimer Querallee 2, 76131 Karlsruhe, Germany
}

\begin{abstract}
A B S T R A C T
Wet compression moulding (WCM) provides high-volume production potential for continuous fibre-reinforced composite components via simultaneous draping and infiltration. Experimental and theoretical investigations proved strong mutual dependencies between resin flow and fabric deformation, which are not fully understood yet. This limits development of suitable process simulation methods and applies in particular for the characterisation of infiltrated bending behaviour - essential for an accurate prediction of draping effects. Therefore, a comparative characterisation of the bending behaviour of dry and infiltrated woven fabrics is presented using a modified cantilever and a rheometer bending test. Experimental results reveal both, rate- and viscosity-dependencies. A comparison of the quantitative results exposed an explicable systematic deviation between the two tests, whereas qualitative results are comparable. Finally, Finite Element forming simulations, comprising two bending models corresponding to cantilever and rheometer test are performed to evaluate the experimental findings on component level.
\end{abstract}

Keywords:

Textile bending characterisation

Forming

Fabrics/textiles

Process simulation

Finite element analysis (FEA)

\section{Introduction}

Wet compression moulding (WCM) provides high-volume production potential for continuous fibre-reinforced components. Due to simultaneous draping, infiltration and curing (viscous draping), low cycle times can be achieved [1-3]. The investigated thermoset-based WCM process consists of five process steps (Fig. 1), similar to the process investigated by Bergmann et al. $[1,4]$ and already applied within the automotive industry.

Although experimental and theoretical investigations proved strong mutual dependencies between the material behaviour and key process parameters (e.g. resin amount and resin application position/technique, infiltration time, tool settings (closing profile, temperature, pressure) and stack weight) [1,3,4], a comprehensive, physics-based understanding of the occurring interactions within the viscous draping stage has not been achieved yet. Since significant cavity pressures develop only towards the end of the tool stroke, the influence of resin on the draping behaviour mainly affects intra-ply and interface behaviour. Consequently, key knowledge on the mutual physical dependencies within the viscous draping stage can be achieved using infiltration dependent material models with negligence of the fluid pressure. This is an adequate assumption since the fluid pressure mainly increases within the last 10 percent of the tool stroke, when draping is almost completed [2]. Consequently, knowledge on the mutual physical dependencies provides the foundation for advanced process simulation methods, which enable lean and purposive process development and part design.

Regarding infiltrated intra-ply behaviour within the viscous draping stage, experimental and numerical investigations carried out in our previous study with a modified bias extension test (IBET) revealed both viscosity- and rate-dependent material response for the infiltrated shear behaviour. Moreover, a significant influence on part level is found [5]. Analogously, similar investigations with regard to the bending behaviour of infiltrated engineering fabrics are expected to provide important knowledge on the WCM process. For pre-impregnated thermoplastic composites, rate- and viscosity-dependent bending behaviour has already been confirmed to be important for an accurate process simulation approach regarding stamp forming $[6,7]$.

In the following, the process related term 'infiltrated' is used consistently throughout this work, to account for the wetting or impregnation of the woven fabric from micro- to macro-scale with resin or silicon oil. Material properties are investigated at homogeneously distributed, discrete viscosities and complete infiltration.

Literature review on experimental bending characterisation. The cantilever test, also referred to as Peirce test $[8,9]$, is commonly applied for bending characterisation of dry woven fabrics [10-12] and non-

\footnotetext{
* Corresponding author.

E-mail address: christian.poppe@kit.edu (C. Poppe).
} 


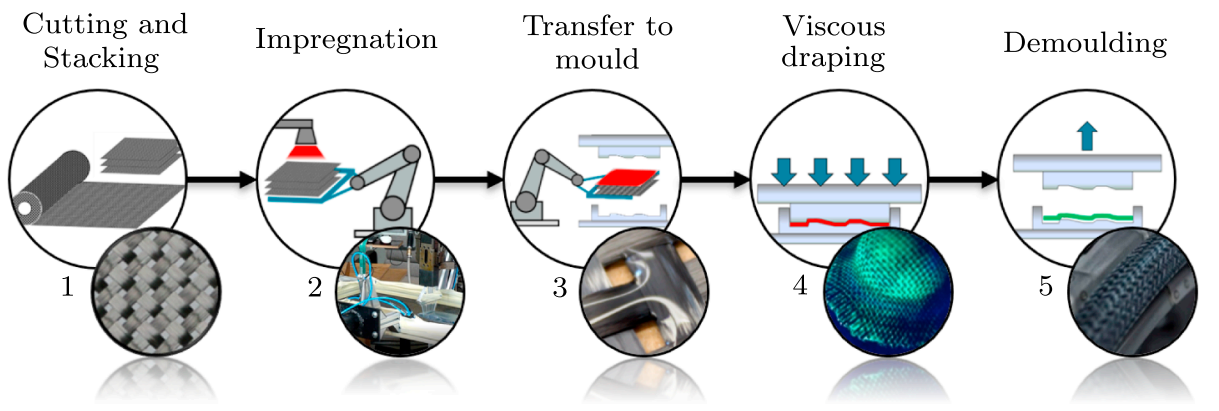

Fig. 1. Schematic illustration of the principle WCM process steps [2]; The cut and stacked laminate (1) is impregnated on the topside (2) and transferred to the mould (3); simultaneous draping and infiltration (viscous draping) shapes the final part (4), which can be demoulded when cured (5). (For interpretation of the references to color in this figure legend, the reader is referred to the web version of this article.)

crimped fabrics [13]. The Peirce method [8] assumes a linear relationship between curvature and bending moment. Bilbao et al. [14] and Liang et al. [15,16] presented additional optical measurement techniques to analyse the shape and deformation of the specimens during testing. They show that the moment-curvature-relation is nonconstant with a maximum at the clamped end. The modified cantilever test presented by Bilbao et al. [14] enables the investigation of elastoplastic bending behaviour by means of variable bending length and the above mentioned optical evaluation. Due to the nonlinear curvature rate distribution along the specimen applied by the cantilever test, additional effort is needed to obtain the bending rate and plastic bending behaviour by means of optical detection and evaluation methods. Therefore, the cantilever test is more suitable for the determination of the elastic bending stiffness [10]. Beyond that, vertical arrangements of the tests are presented e.g. by Dangora et al. [17] to reduce the influence of gravity loadings for small deformations. A comprehensive review on bending characterisation is presented by Boisse et al. [10].

The Kawabata bending test (KES-FB2) [18], and its expansions, impose a constant curvature and curvature rate distribution along the specimens by the rotation of one of the two clamps. This enables direct access to the moment-curvature-relation, even during several loading and unloading cycles. Nonlinear and hysteretic material response is found for several materials $[14,19,20]$ due to internal friction between the rovings and filaments $[21,22]$. In contrast to the cantilever test, the KES-FB2 enables rate-dependent bending characterisation. One important modification of the KES-FB2, the rheometer bending test (RBT), presented by Sachs [6], allows investigation of the rate- and temperature-dependent bending response of thermoplastic composites. Threepoint-bending tests are used for composite materials [23,24]. This however, requires a sufficiently large bending stiffness, which is achieved by either thick laminates or short specimens [10].

Despite the outlined studies, to the author's best knowledge, no attempts have been published yet regarding the characterisation of low viscous infiltrated bending behaviour of engineering fabrics. The investigated viscosity range of $0-250 \mathrm{mPas}$ is significantly lower than comparable pre-impregnated semi-finished products that are investigated in the above outlined studies.

Beyond that, a comparison between the existing results of different characterisation methods, as already available for shear [25] and friction [26], does not exist. Consequently, it is unknown whether different test approaches produce comparable results. Thus, in the first part of this study, dry and infiltrated woven fabrics are characterised and compared in terms of their bending behaviour using a conventional, slightly modified cantilever test and a RBT. Subsequently, a qualitative and quantitative comparison between the experimental results of both tests is presented and their individual advantages and drawbacks are outlined. Finally, both tests are assessed in terms of their suitability regarding infiltrated bending characterisation for Finite Element (FE) forming simulation.

Literature review on numerical modelling. The usage of FE forming simulation enables a detailed analysis of the resulting deformation by means of constitutive modelling of the material behaviour, considering process and boundary conditions [7,27-29]. Modelling of macroscopic forming behaviour is based on constitutive modelling of the relevant deformation mechanisms, which are usually separated into intra-ply mechanisms for the single plies (membrane and bending) and interface mechanisms between the stacked single plies [27,30]. Several modelling approaches have been published in recent years. Regarding engineering textiles, studies have been presented among others by Boisse et al. [31], Hamila et al. [32], Dangora et al. [17], Schirmaier et al. [33] and Harrison et al. [34]. Regarding bending behaviour, both purely elastic models $[27,35,36]$ as well as rate-dependent modelling approaches [7,37] are published, mostly in the field of thermoplastic UDTapes. Comprehensive reviews regarding FE forming simulation modelling approaches are presented by Boisse et al. [10,38] and Bussetta et al. [39].

In this work, a hypoviscoelastic model based on a Voigt-Kelvin approach by Dörr et al. [7] is adapted using nonlinear material parameters to account for experimentally obtained rate- and viscosity-dependent bending behaviour. This bending model is subsequently applied to a generic geometry using a macroscopic FE forming simulation implemented in ABAQUS. Membrane and bending behaviour are decoupled by means of superimposed membrane and conventional shell elements. Recent publications [10,40] show that transverse shear deformation of the single ply is a key mechanism, which cannot be ignored in the shell formulation. Based on the applied shell theory and the limitations prescribed by the framework of ABAQUS' vUGENS subroutine, the constitutive equations for viscoelastic bending presented in Section 3.2 pertain solely to the plate part of the shell element [7]. A suitable transversal shear stiffness value is estimated based on the plate part of the applied bending model. The consequence of transverse shear slippage between fibres is mainly taken into account by characterising and modelling the reduced homogenised bending stiffness of the ply.

\section{Experimental characterisation of infiltrated bending behaviour}

In this study a Sigmatex (GB) $12 \mathrm{~K}$ carbon plain weave woven fabric without binder is used. It is made of T700SC-12K-50C Zoltek fibers. The areal weight is $330 \pm 10 \mathrm{~g} / \mathrm{m}^{2}$ and roving width measures $5.0 \pm 5 \mathrm{~mm}$, while the initial spacing measures $2.0 \pm 3 \mathrm{~mm}$. The initial thickness of the single plies measures $0.3 \mathrm{~mm}$. Silicone oils (Quax $\mathrm{GmbH}$, Otzberg, Germany) with discrete viscosities between 20 and $250 \pm 3 \mathrm{mPas}$ are used as test fluids. This avoids additional heating of the test benches and resulting uncertainties due to inhomogeneous temperature distributions. The viscosity range is derived from the process temperatures [5]. Plate-to-plate rheometer tests showed no rate-dependency of the viscosity of the applied silicon oils within a shear rate range of $1-1000 \mathrm{~s}^{-1}$. Alls tests were carried out at the Fraunhofer Institute for Chemical Technology (ICT) in Pfinztal, Germany.

In the first part of the experimental investigations, the above outlined characterisation set-ups, namely the Cantilever (Section 2.1) and Rheometer tests (Section 2.2) for the characterisation of dry and infiltrated bending behaviour are performed and their results are discussed separately. Subsequently, both approaches are compared, 


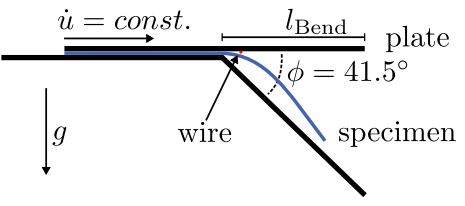

(a)

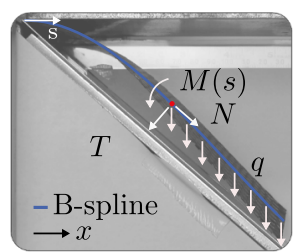

(b)
Fig. 2. (a) Schematic illustration of the used cantilever test; (b) optical evaluation method: Bending moment $M(s)$ resulting from the specimen's weight per unit length $q$ on a cross section for the curvilinear coordinate $s$ (similar to [41]) on a fitted B-spline. (For interpretation of the references to color in this figure legend, the reader is referred to the web version of this article.)

discussed and their suitability regarding infiltrated bending characterisation is evaluated (Section 2.3).

\subsection{Cantilever tests}

In this study, a slightly modified cantilever test is applied, which contains an additional wire as illustrated in Fig. 2(a). Typically, the specimens are clamped between two plates and pushed over an $41.5^{\circ}$ edge at constant speed $(\dot{u}=2 \mathrm{~mm} / \mathrm{s})$. The specimen is moved by friction with the upper plate, thus the application of a small amount of transversal shear on the specimen cannot be completely excluded. The width of the specimens measures $100 \mathrm{~mm}$. Two different fibre orientations are investigated $\left(0 / 90^{\circ}\right.$ and $\left.\pm 45^{\circ}\right)$. Preliminary experiments reveal that the infiltrated contact interface can lead to sticking between the specimen and the top plate. Therefore, a thin wire $(\varnothing 0.5 \mathrm{~mm})$ is positioned just behind the edge $(7 \mathrm{~mm})$ on the underside of the top plate (Fig. 2(a)). This ensures a reproducible test procedure to be carried out, as the detachment from the top plate is comparable for all tests. After the free end of the specimen is initially detached by contact with the wire, the test can be performed as usual. Therefore, the wire is only used for the detachment form the top plate and does not have further contact with the specimen. The bending stiffness $B_{\mathrm{w}}^{\text {Can }}$ normalised by its width, is calculated by means of the overhang length $l_{\text {Bend, }}$,

$B_{\mathrm{w}}^{\mathrm{Can}}=\frac{F_{\mathrm{g}}}{b} \frac{l_{\text {bend }}^{3}}{8} \frac{\cos (\phi / 2)}{\tan (\phi)} \quad$ with $\quad F_{g}=g \frac{m_{\mathrm{spec}}+m_{\mathrm{resin}}}{l_{\text {bend }}}$,

which is measured when the free end of the specimen touches the lower plate (see Fig. 2(a)). In standard commercial devices, $41.5^{\circ}$-plates are used. An empirical correction factor for large deformations $(\cos (\phi / 2))$ was introduced by Peirce [8]. Boisse et al. [10] showed for a specific case that the usage of this empirical correction factor minimises the resulting errors to $4.4 \%$ for a deflection angle of 60deg in comparison to a FE solution. The length-related gravity force $F_{\mathrm{g}}$ of the specimens is determined by measurement of the infiltrated specimen weight $m_{\text {spec }}+m_{\text {resin }}$ prior and after the test (see Eq. (1)))) to account for possible weight changes during testing.

Optical evaluation method. An optical evaluation method similar to the approaches presented by Bilbao et al. [11,14] and Liang et al. [15] is implemented, to quantify the curvature distribution along the specimens during the cantilever experiments. For this purpose, a shape detection algorithm in combination with a spline fit is implemented using an inhouse code within MATLAB. The moment $M(s)$ at every point $\mathrm{p}$ on the curvilinear coordinate $s$ (cf. Fig. 2(b)) can be calculated by

$M\left(s_{\mathrm{p}}\right)=\int_{s_{\mathrm{p}}}^{L} q\left(s-s_{\mathrm{p}}\right) \cos (\phi(u)) \mathrm{d} s \quad$ and $\quad \kappa\left(s_{\mathrm{p}}\right)=\frac{f^{\prime \prime}}{\left(1+f^{\prime 2}\right)^{2 / 3}}$,

where $q$ is the weight per unit length, $L$ the total length of the profile. Regarding the calculation of the curvature $\kappa\left(s_{\mathrm{p}}\right), f^{\prime}$ and $f^{\prime \prime}$ denote the first and second derivative of the bending-moment-curve fitted with a B-spline. The analytical solution is based on the Kirchhoff theory. Thus, the cross section remains normal to the mid-surface during

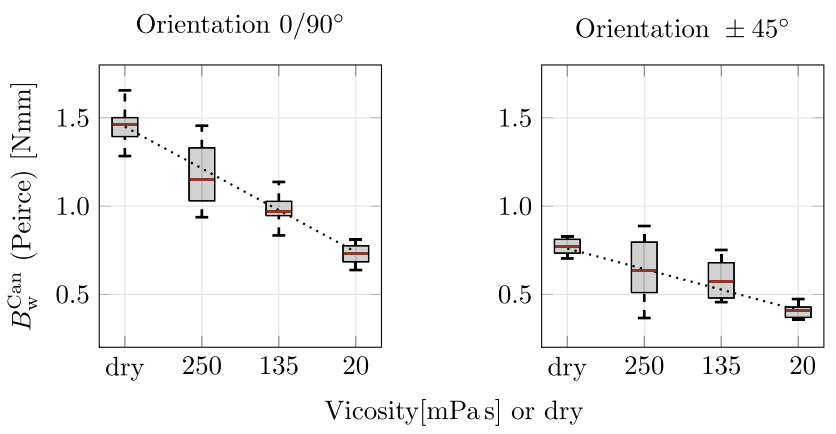

Fig. 3. Results of the cantilever tests according to Peirce. The red lines within the Boxplots represent median, upper and lower bounds of the 25 and 75 percent quantile, and the whiskers indicate the total value range of the bending stiffness $B_{\mathrm{w}}^{\text {Can }}$. (For interpretation of the references to color in this figure legend, the reader is referred to the web version of this article.)

deformation. Therefore, transverse shear is not considered with this approach [41]. The average curvature rate $\dot{\kappa}$ is estimated by means of the curvature history,

$\dot{\kappa} \approx \frac{\Delta \bar{\kappa}}{\Delta t} \quad$ with $\quad \Delta \bar{\kappa} \approx \frac{1}{\left(l_{b, t_{1}}-l_{b, t_{1}}\right)}\left(\sum_{i=l_{b, t_{1}}^{\max }}^{l_{b, t_{1}}^{\min }}\left|\kappa_{i, t_{2}}-\kappa_{i, t_{1}}\right|\right)$ for $t_{2}>t_{1}$,

where the incremental average curvature difference $\triangle \bar{\kappa}$ is divided by the incremental time period $\triangle t=t_{2}-t_{1}$ between the two compared states. Due to low light exposure conditions directly under the top plate, the curvature rate could only be detected after $1 / 3$ of the experiment duration.

Execution procedure. The execution of the experiments with the infiltrated specimens did not cause major problems compared to the dry ones. However, a constant infiltration time, an exact amount of resin and its homogeneous distribution across the specimen are crucial. It cannot be determined whether a resin flow takes place through the specimens (rovings) during the tests. No dripping of test fluid is detected during the tests with regard to the investigated material combination. This might result from the rovings' good capability to absorb the fluid [5].

Experimental results. A comparison between the experimentally determined bending stiffnesses of dry and infiltrated specimens (Eq. (1)) is shown in Fig. 3 using boxplots. The black dotted lines are linear regressions using the median values. All tests are conducted 7-10 times. Bending stiffness of infiltrated specimens decreases significantly compared to dry specimens, for both fibre orientations. The lower the viscosity of the infiltrated specimens, the lower the bending stiffness. The absolute reduction within the stiffness values of $0 / 90^{\circ}$ specimens is about twice of the $\pm 45^{\circ}$ ones, whereas the relative reduction is comparable. A comparison with the results of the optical measurements is shown in Fig. 4 by means of the optically detected moment-curvature-

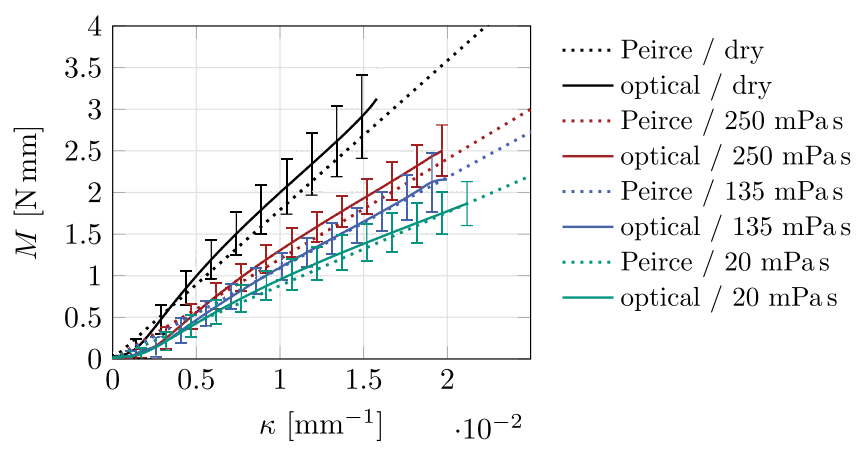

Fig. 4. Comparison between the optical detected moment-curvature-curves and the linear predictions of the Pierce method. (For interpretation of the references to color in this figure legend, the reader is referred to the web version of this article.) 
Table 1

Optically estimated curvature rates (cantilever test).

\begin{tabular}{ll}
\hline$\dot{\kappa}_{\text {dry }}^{\text {Can }}$ & $3.3( \pm 1.4)\left[10^{-4} \cdot \mathrm{mms}^{-1}\right]$ \\
$\dot{\kappa}_{20}^{\text {Can }}$ & $5.2( \pm 1.8)\left[10^{-4} \cdot \mathrm{mms}^{-1}\right]$ \\
$\dot{\kappa}_{135}^{\mathrm{Can}}$ & $5.9( \pm 2.1)\left[10^{-4} \cdot \mathrm{mms}^{-1}\right]$ \\
$\dot{\kappa}_{250}^{\mathrm{Can}}$ & $6.7( \pm 2.2)\left[10^{-4} \cdot \mathrm{mms}^{-1}\right]$ \\
\hline
\end{tabular}

curves. The Peirce straights $\left(M=B_{\mathrm{w}}^{\mathrm{Can}} \cdot \mathcal{\kappa}\right)$ match well the optical results. This validates the general capability of the applied optical detection method.

Furthermore, Eq. (3) is used to estimate the average curvature rates $\dot{\kappa}$ during the cantilever test according to Table 1 . Since the bending stiffness and weight of the specimens vary, so does the averaged curvature rate. The dry specimens are exposed to the lowest rates, while the low viscous infiltrated ones are exposed to the highest.

Discussion of the cantilever test results. Experimental results reveal a consistent correlation between infiltration viscosity of the specimens and their bending stiffness for two different fibre orientations. Bending stiffness of the rovings is mostly determined by the friction state between the filaments. Consequently, an infiltration of these contact interfaces reduces the frictional forces (lubrication), and therefore the bending stiffness of the rovings or specimens, respectively. Similarly, it is likely to find according correlations between bending stiffness and infiltration for unidirectional non-crimped fabrics (UD-NCF).

The optically determined moment-curvature-curves are in good agreement with the analytical solution provided by Peirce (cf. Fig. 4). The curves' shapes are consistent with the results of Liang et al. [15]. Thus, the implemented optical evaluation presented by Liang et al. [16] provides reliable results. The optical measurement results confirm that cantilever tests conducted with infiltrated specimens automatically involve varying rates during testing. This is neglected during the common evaluation procedure for dry specimens.

\subsection{Rheometer bending tests}

An enlarged rheometer bending test similar to the one presented by Sachs et al. [6] is applied according to Fig. 5. Tests with specimens containing a free test area of $70 \times 60 \mathrm{~mm}$ are conducted. The enlarged set-up is recommended for coarser fabrics to increase the number of cross points and therefore the reproducibility of the experiments. The corresponding curvature rates can be assessed, based on the assumption that a perfect arc with a constant curvature is formed along the specimen, via equation
Table 2

Investigated curvature rates based on Eq. (4).

\begin{tabular}{lccc}
\hline$\dot{\gamma}_{i}^{\text {Rheo }}[\mathrm{rpm}]$ & 0.1 & 1 & 10 \\
$\dot{\kappa}_{i}^{\text {Rheo }}\left[(\mathrm{mms})^{-1}\right]$ & $1.65 \cdot 10^{-4}$ & $1.65 \cdot 10^{-3}$ & $1.65 \cdot 10^{-2}$ \\
\hline
\end{tabular}

$\frac{\mathrm{d} \kappa_{i}}{\mathrm{~d} t}=\frac{\dot{\gamma}_{i}^{\text {Rheo }}(t)}{2 R \cdot \cos ^{2}\left(\gamma_{i}(t) / 2\right)} \quad$ with $\quad \kappa_{i}=\frac{\tan \left(\gamma_{i}^{\text {Rheo }}(t) / 2\right)}{R}$,

where $\gamma$ provides the rotation angle of the rheometer along with the rheometer bending radius $R$. This implies that the clamping is assumed to be frictionless and that the bending stiffness is constant (homogenous) along the specimen. Three discrete angular velocities are investigated, since rate-dependency of the infiltrated material is expected (Table 2).

Special attention is be paid to the clamping, to reduce friction as far as possible. To ensure this, both sides of the specimens are taped symmetrically to create a more homogeneous surface as shown in Fig. 5(b). Furthermore, care is taken to avoid wetting of the contact interfaces. Otherwise, this could lead to increased friction between fabric and clamping, which has a reported effect on the obtained results [6], as higher bending moments would be obtained. To ensure a complete and homogeneous fluid distribution, the specimen's test area remains within the fluid for one minute prior to testing. Five to eight specimens are tested for every configuration, depending on the actual scatter. In addition to the first deflection, further 2.5 cycles between $-60^{\circ}$ and $60^{\circ}$ are tested according to Fig. 5(c), to investigate the hysteresis behaviour of the dry and infiltrated specimens. The dissipation energy $W_{\text {diss }}$ per cycle is used to evaluate the hysteresis behaviour. The dissipation energy $W_{\text {diss }}$ is represented by the enclosed area of one full cycle according to

$W_{\text {diss }}=\int_{\gamma_{0}}^{\gamma_{1}} M(\gamma) d \widetilde{\gamma}$,

which can be calculated as the integral of the measured moment-anglecurves $M(\gamma)$.

Execution procedure. The execution of the rheometer tests with infiltrated woven fabrics did not cause problems and can therefore be recommended (cf. Section 2.3). In addition, only minor dropping could be detected during the tests, wherefore a constant, homogeneous fluid distribution is achieved.

Experimental results. Regarding the first deflection, a significant influence of both, infiltration viscosity and bending rate is observed (cf. Fig. 6). The bending stiffness of the low viscous infiltrated specimens decreases along with the fluid's viscosity as shown in Fig. 6(a). Moreover, bending stiffness shows rate-dependent response (cf. Fig. 6(b)). It (a)

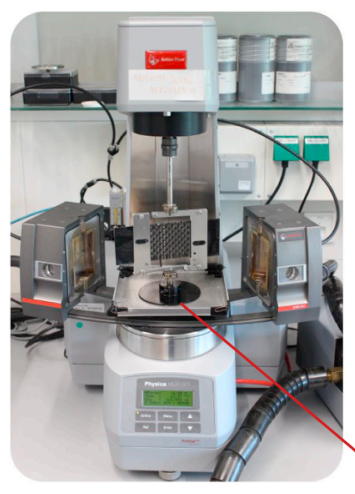

(b)

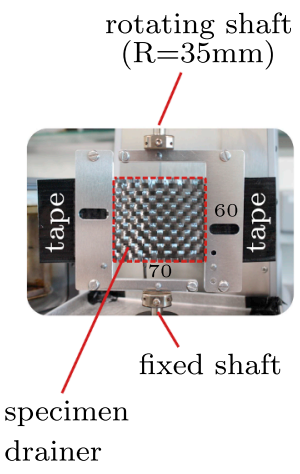

(c)

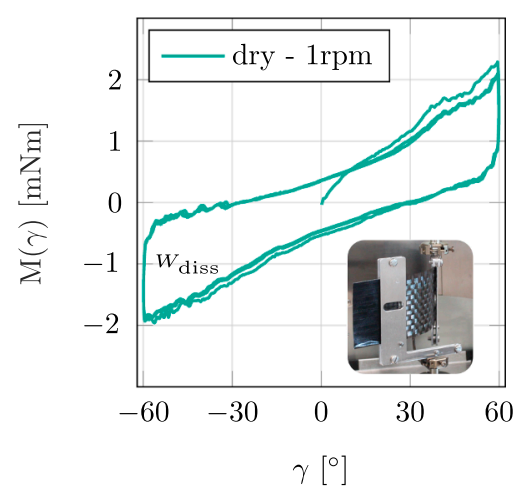

Fig. 5. (a) Anton Paar MCR501 rheometer with enlarged bending test based on [6]; (b) detailed picture of the clamped specimen; (c) exemplary plot of the measured data. (For interpretation of the references to color in this figure legend, the reader is referred to the web version of this article.) 
(a) Impact of infiltration

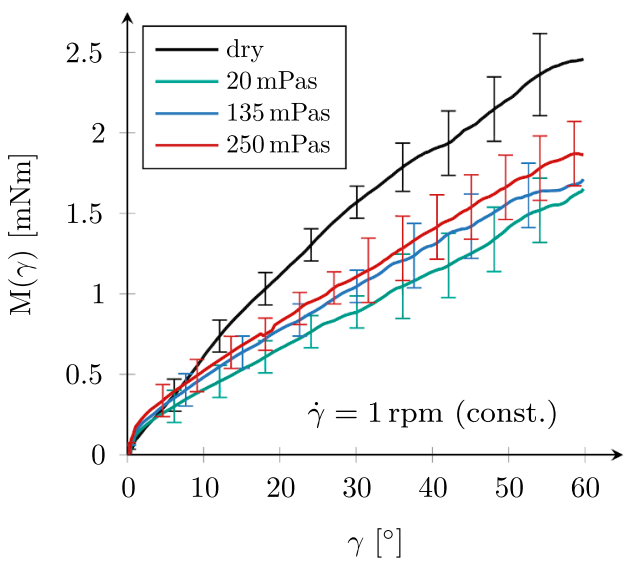

(b) Impact of bending rate

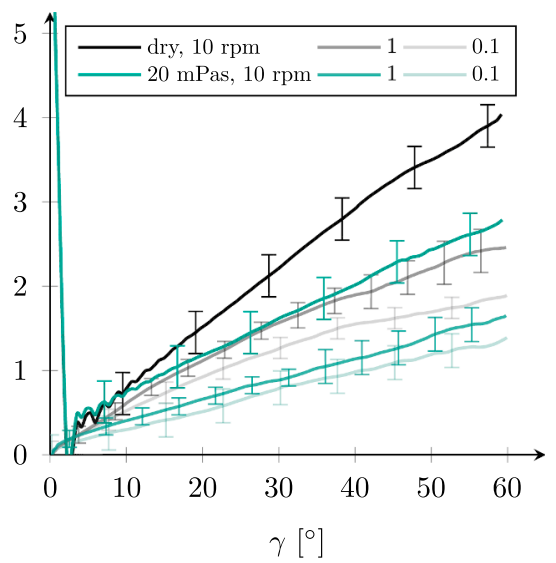

Fig. 6. Experimental results of the rheometer tests; (a) Impact of the infiltration viscosity at constant rate (1 rpm); (b) Impact of the bending rate (dry and $20 \mathrm{mPas)}$ on the moment-angle-curve $M(\gamma)$. (For interpretation of the references to color in this figure legend, the reader is referred to the web version of this article.)

(a) overview

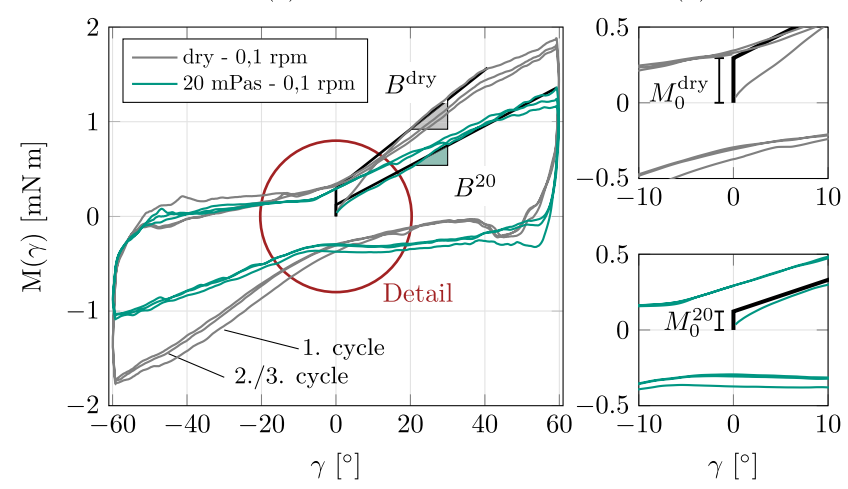

Fig. 7. (a) Exemplary comparison between the hysteresis behaviour of dry and infiltrated specimen for 3 cycles; (b) corresponding initial threshold moment $M_{0}$ based on [22,14]. (For interpretation of the references to color in this figure legend, the reader is referred to the web version of this article.)

is worth mentioning that the dry specimens show a distinct rate-dependency. Regarding the results of the hysteresis behaviour, similar dependencies in terms of infiltration viscosity and bending rate are found. However, the differences are slowly diminishing with increasing number of load cycles (cf. Fig. 8). The infiltration significantly reduces the initial threshold moment $M_{0}$ (cf. Fig. 7(b)), evaluated according to $[14,22]$. As Fig. 7 shows, the curves of the second and third cycle are almost identical, which indicates that an almost stationary state of the hysteresis behaviour is reached within the third cycle. Consequently, the dissipation energies $W_{\text {diss }}$ remain nearly constant between the second and third cycle. The intensity of this effect depends on the viscosity of infiltration. The dependencies between dissipated energy, infiltration viscosity and bending rate (cf. Fig. 8) show similar qualitative dependencies as results of the first deflection (cf. Fig. 6(a), (b)). Consequently, the bending behaviour of the woven fabric is shown to be viscoelastic-plastic, even for dry specimens.

Discussion of the rheometer results. As outlined in the discussion of the cantilever test in Section 2.1, internal (micro) friction between the rovings and filaments is the main mechanism governing the bending behaviour of woven fabrics. This implies transverse shear deformation on macroscopic scale. In this regard, infiltration of the contact interfaces between the filaments and within the rovings alters the frictional behaviour and therefore decreases the bending stiffness of the specimen. The impact of rate-dependency is similarly noticeable within dry and infiltrated fabrics. This suggests that mainly the fibre coating is

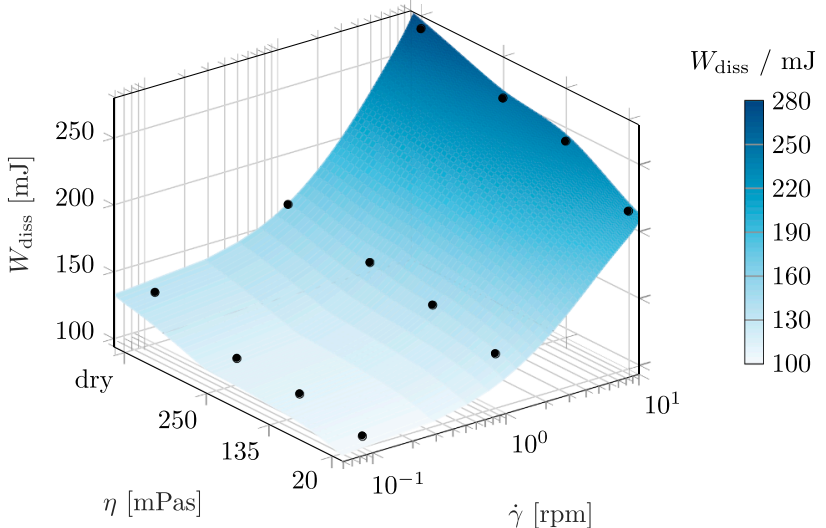

Fig. 8. Surface plot and corresponding data points (black marker) of the dissipation energies $W_{\text {diss }}$ of the last rheometer cycle for varying viscosities $\eta$ and angular velocities $\dot{\gamma}$. (For interpretation of the references to color in this figure legend, the reader is referred to the web version of this article.)

responsible for the measured rate-dependency and not primarily an infiltration-dependent micro friction between the filaments. Consequently, infiltration and coating contribute collectively to the measured viscosity- and rate-dependent material behaviour. This effect will probably not be measurable for pre-impregnated semi-finished products, since the viscosity of these matrices is significantly higher.

Furthermore, dissipation energies $W_{\text {diss }}$ during multiple load cycles and initial threshold moments $M_{0}$ are additionally investigated based on the suggestions in literature presented by Grosberg et al. [22], Dahl et al. [21] and Bilbao et al. [14]. Results show consistent impact of the viscosity on both parameters. The tendency of the hysteresis behaviour towards a stationary state could originate from levelling phenomena on the contact interfaces and from the coating between the filaments as Tourlonias et al. showed on single fibres [42]. The implications of these effects are also considered by Cao et al. [25] during their shear behaviour benchmark study using the term 'mechanical conditioning'. Consequently, the measured bending behaviour is viscoelastic-plastic. This was not expect on beforehand for the dry specimens.

\subsection{Comparison of experimental results}

In this section, both tests, namely the Cantilever and RBT are compared in terms of their characterisation results. Their suitability 
(a)

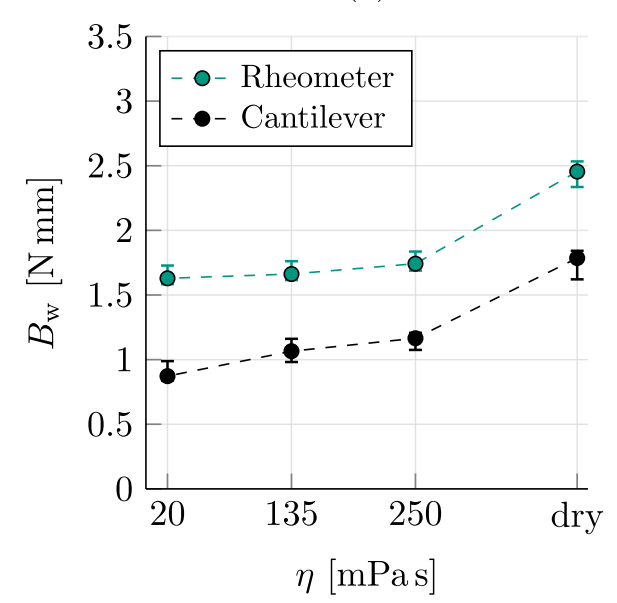

(b)

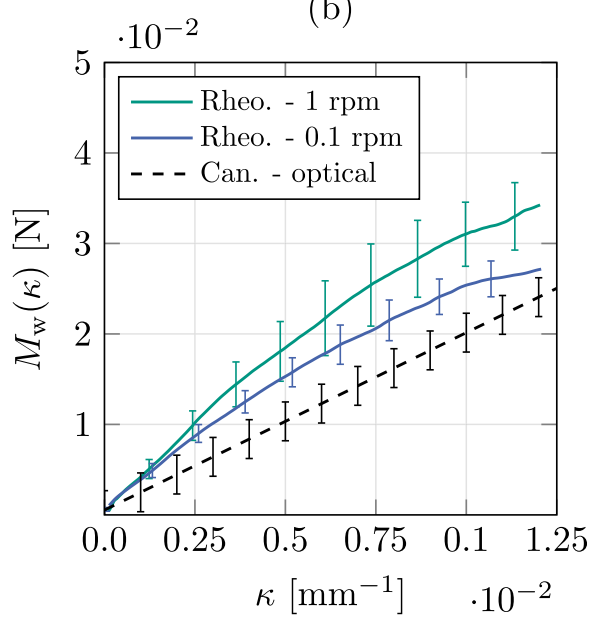

Fig. 9. Comparison of the experimental results; (a) direct comparison of the normalised bending stiffnesses $B_{\mathrm{w}}$ (median values) at corresponding rates (cf. Table 2); (b) exemplary width-based moment-curvature-curves for the dry specimens. (For interpretation of the references to color in this figure legend, the reader is referred to the web version of this article.)

regarding the characterisation of infiltrated bending behaviour is discussed subsequently. A direct comparison between the two tests is enabled by additional optical determination of the curvature rates of the cantilever test corresponding to each infiltration viscosity (cf. Fig. 4). These curvature rates are used as basis, and the corresponding bending stiffness values measured with the RBT are interpolated accordingly.

Since both tests used differently dimensioned specimens, the bending stiffnesses are plotted normalised by the width (cf. Fig. 9(a)). The results show a qualitative, but no quantitative correlation. Infiltration reduces the bending stiffness in both cases. Still, bending stiffness measured by the rheometer test is systematically higher. Consequently, the normalised moment-curvature-curve $M_{\mathrm{w}}(\gamma)$ of the cantilever tests (cf. Fig. 9(b)) remains below the rheometer curves, even though the average curvature rate values of the cantilever tests lie between the rheometer rate $\left(\dot{\kappa}_{\text {Rheo. }}^{1 \mathrm{rpm}}>\dot{\kappa}_{\text {Can. }}>\dot{\kappa}_{\mathrm{Rheo} .}^{0.1 \mathrm{rpm}}\right)$.

Discussion of the compared experimental results. The effect of infiltration on the bending behaviour of woven fabrics has been investigated by means of two approaches. The bending stiffnesses determined by the RBT are about $25-44 \%$ higher than the ones from the cantilever test. This difference is significantly higher than the uncertainties arising from the optical evaluation or averaging of the curvature rates. The systematic deviation indicates that the differences are caused by the test benches themselves including their applied boundary conditions. A potential influence of the specimen size cannot be excluded completely. However, it is assumed to be of minor importance since the specimen sizes are large enough to provide a sufficient number of crosspoints in both cases.

Three contributing effects are identified to explain the diverging results (cf. Fig. 10). First, friction within the clamping of the rheometer bending test (cf. Fig. 10 (1)) has a reported impact on the measured result [6], leading to increased values. Since complete frictionless within the contact areas cannot be achieved during the experimental trials, we expect that friction contributes at least partly to an increased bending stiffness when measured by the RBT.

Regarding the cantilever test, the fabric could already be pre-compacted when tested [14] due to the weight of the top plate (cf. Fig. 10 (2)). This reduces thickness $t_{2}$ in comparison to the initial thickness $t_{0}$ which is commonly used for the evaluation. Compaction affects the physical and geometrical properties of the fabric due to an increased transversal shear stiffness and a reduced second moment of area. While the physical effect leads to an increased bending stiffness, the latter leads to the contrary. Only additional experimental investigations can enable an evaluation of the individual importance and relevance of the discussed effects. However, the actual compaction during the tests could not be measured in this study. In any case, it is important to emphasise that higher compaction forces, despite the ones needed to apply proper boundary conditions, should be avoided during cantilever tests. Comparing effects 1 and 2 (cf. Fig. 10), we expect the impact of compaction to be more decisive than the effect friction with the clamps of the RBT.

Finally, the infiltration itself could lead to differences between the two test results. Potentially, a flow of the test fluid within the specimen does not directly contribute to the measured results of the RBT. However, it does directly contribute to the cantilever test, due to possible changes in the weight distribution or loss of mass within the specimens. A flow within the specimens or major draining of the specimens could not be detected during the experiments. Moreover, the systematic deviation is also valid between the dry specimens, where a

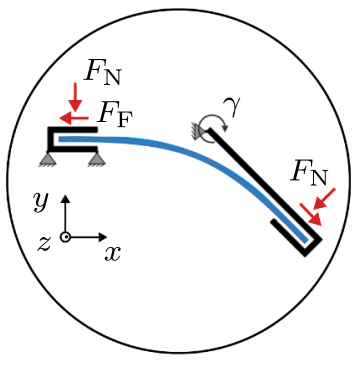

1. Friction in clamping

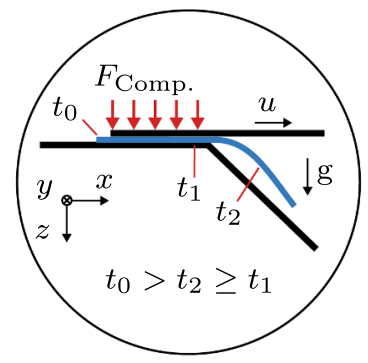

2. Specimen compaction

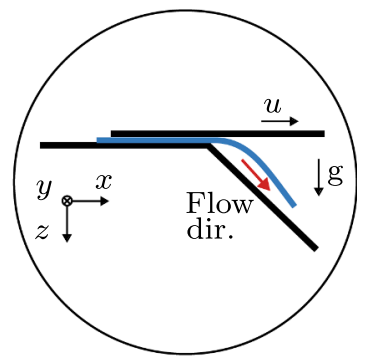

3. Infiltration

Fig. 10. Assumed contributions to the systematic deviation between the cantilever and RBT results; (1), (2) systematic effects; (3) infiltration-specific effect. (For interpretation of the references to color in this figure legend, the reader is referred to the web version of this article.) 
Table 3

Summarised evaluation of the two tests; Cantilever without optical evaluation.

\begin{tabular}{c|c|c|c|c|c}
\hline Setup & $\begin{array}{c}\text { Exp. } \\
\text { effort }\end{array}$ & $\begin{array}{c}\text { Infiltration } \\
\text { suitability }\end{array}$ & $\begin{array}{c}\text { Measur. } \\
\text { accuracy }\end{array}$ & $\begin{array}{c}\text { Viscoelastic } \\
\text { behaviour }\end{array}$ & $\begin{array}{c}\text { Recommended } \\
\text { application }\end{array}$ \\
\hline Cantilever & $\bullet \bullet \bullet$ & $\bullet \bullet$ & $\bullet$ & no & Quick parameter estimation \\
Rheometer & $\bullet \bullet$ & $\bullet \bullet \bullet$ & $\bullet \bullet \bullet$ & $\bullet \bullet \bullet$ & $\begin{array}{c}\text { In-depth material analysis } \\
\text { (l) }\end{array}$ \\
\end{tabular}

possible impact of infiltration is excluded. Consequently, the impact of infiltration is expected to be of minor importance in this case.

Beyond the above outlined differences regarding the experimental results, both tests are not equally recommendable or suitable in terms of infiltrated bending characterisation of woven fabrics, as summarised in Table 3 .

The cantilever test, without optical evaluation, provides a fast and well-known approach to determine the elastic bending behaviour for dry and infiltrated specimens. Preparation, execution and evaluation efforts are low, however measurement accuracy is considerably lower compared to the RBT and viscous material properties are not measurable. Moreover, the specimens are exposed to unknown compaction with effects the obtained results. Thus, the cantilever tests can only be recommended for a substantial estimation of the elastic dry and infiltrated bending behaviour. The RBT is especially recommended in cases when more fundamental material analysis of the viscoelasticplastic bending behaviour of dry and infiltrated woven fabrics is required (cf. Figs. 6-8). Preparation effort is higher due to the taping of the specimen but measurement accuracy, in terms of deflection angle and bending moment, is excellent. Special attention should be paid to the infiltration state of clampings (keep dry) and their superimposed friction[6], which cannot be directly measured with current experimental setups. Furthermore, a homogeneous infiltration should be present, which could be achieved with the investigated material, but might be more challenging with less absorbing materials.

\section{Numerical investigation}

\subsection{FE forming simulation model}

To assess the process relevance of the experimental findings outlined in Section 2, a numerical study is conducted by means of FE forming simulation with one and two plies for a generic box-shaped geometry. On the macroscopic scale, the intra-ply mechanisms, namely membrane and bending behaviour, have to be decoupled, since in-plane fibre tensile stiffness is several decades higher than bending stiffness. This is achieved by using superimposed membrane and shell elements to represent the single ply of the stacked laminate [7]. Interface mechanisms, namely adhesion and friction, connect the single plies within the stack. The outlined approach is implemented by means of three user-subroutines within the commercially available FE solver ABAQUs, to account for a user defined membrane, bending and contact behaviour (cf. Tables 2 and Table 4).

The membrane model is parametrised according to previously published experimental shear characterisation results [5] for the same material as investigated in the present study. To limit the numerical investigations to the influence of bending behaviour, only the dry parameter set is used for the membrane properties during all simulations. This implies a hyperelastic membrane behaviour.

For bending modelling, an existing hypoviscoelastic model presented by Dörr et al. [7] is applied and extended to account for experimentally measured viscosity-dependent bending behaviour. In addition to the already implemented rate-dependency following a VoigtKelvin approach in combination with a Cross model, a nonlinear elasticity is implemented. The observed plasticity behaviour is neglected in this numerical study because the visco-elasticity is expected to be the more sensitive mechanism, as the results presented in Section 2.2 indicate. Moreover, the experimentally obtained hysteresis behaviour is not taken into account throughout this first approach, which is a common assumption.

Regarding the contact behaviour, tool-ply (TP) interaction is implemented via an ABAQus built-in approach $\left(\mu_{\mathrm{TP}}=0.25\right)$, whereas the ply-ply (PP) contact is implemented by means of an in-house available contact model of Dörr et al. [30] based on the penalty method. The critical tangential stress $\tau_{\text {crit }}$, which is regularised by a yield function, is given by

$\tau_{\text {crit }}=\mu^{\mathrm{PP}} \cdot p+\eta^{\mathrm{PP}} \cdot v+\tau_{0}^{\mathrm{PP}}$

where $\mu_{\text {Ply }}$ is the tangential coefficient of friction and $\tau_{0}$ accounts for the adhesion. Rate-dependencies are suppressed within the contact model, which limits rate-dependency to the applied bending model $\left(\eta^{\mathrm{PP}} \rightarrow 0\right)$. To account for the interdependency between contact and bending behaviour [27], two sets of ply-ply contact parameters are used according to Table 7 (Appendix A) Regarding the low contact setting, the adhesion parameter $\tau_{0 \text {,low }}^{\mathrm{PP}}$ is parametrised by experiments with dry woven fabrics [44], whereas $\tau_{0 \text {, high }}^{\text {PP }}$ is set to suppress relative slip between the plies (high contact setting). In this manner, the low contact setting represents a process situation in which plies can slide relatively to each other easily, e.g. due to lubrication with low viscous resin within the WCM process. In contrast, the high contact setting represents a process situation where plies mostly stick together and relative slip is therefore prevented, for example due to the lubrication with a partly cured resin or an additional application of chemical binders. The contact parameters are kept constant in both cases to focus on the bending behaviour exclusively. In the following, the fundamental equations and modifications for the infiltrated bending behaviour are presented and parametrised. Subsequently, numerical results of the sensitivity study are shown and discussed.

\subsection{Constitutive equations and modification for the bending behaviour}

A hypoelastic bending model in combination with a Voigt-Kelvin approach is used within a non-orthogonal curvilinear fibre-parallel frame given by the normalised covariant base vectors $\left\{\boldsymbol{g}_{i}^{*}\right\}$ and the corresponding dual contravariant base vectors $\left\{\boldsymbol{g}^{* i}\right\}$. The elastic objective Cauchy stress rate $\sigma^{\nabla}$ within the fibre-parallel frame is given by

$\left[\sigma^{\nabla}\right]_{\left\{\mathbf{g}_{i}^{*} \otimes \mathbf{g}_{j}^{*}\right\}}=[C]_{\left\{\mathbf{g}_{i}^{*} \otimes \mathbf{g}_{j}^{*} \otimes \mathbf{g}_{k}^{*} \otimes \mathbf{g}_{l}^{*}\right\}}:[D]_{\left\{\mathbf{g}^{* k} \otimes \mathbf{g}^{* l}\right\}}$,

where $\mathbb{C}$ is the fourth order elasticity tensor and $\boldsymbol{D}$ the rate-of-deformation tensor. The incremental elastic Cauchy stress $\Delta \sigma^{\mathrm{e}}$ in the fibreparallel frame is obtained by integration of Eq. (7) in time, which yields

Table 4

Outline and origin of the applied material models.

\begin{tabular}{|c|c|c|c|}
\hline Deformation mechanism & Material formulation & Suboutine ABAQUS & Reference $\&$ modification $(+)$ \\
\hline Membrane & hyperelastic & VUMAT & [5] (dry) \\
\hline Bending & hypoviscoelastic & VUGENS & $\left.[7](+) B_{i}(\eta), \dot{\gamma}\right)$ \\
\hline Contact (ply-ply) & penalty method & VUINTERACTION & {$[30,43]$ (low, high) } \\
\hline
\end{tabular}


$\left.{ }^{t+d t} \Delta \sigma^{\mathrm{e}}\right]_{\left\{g_{i}^{*} \otimes \mathrm{g}_{j}^{*}\right\}}=[\mathbb{C}]_{\left\{g_{i}^{*} \otimes g_{j}^{*} \otimes g_{k}^{*} \otimes g_{l}^{*}\right\}}:\left[{ }^{t+d t} \Delta \varepsilon\right]_{\left\{g^{* k} \otimes g^{* l}\right\}}$,

where $\Delta \varepsilon$ is the strain increment in the fiber parallel frame, which is obtained from the strain increment in Green-Naghdi's frame $\left\{\boldsymbol{e}_{i}\right\}$ (ABAQUS) by means of the normalised right stretch tensor $\boldsymbol{U}_{\mathrm{n}}$ by

$\left.{ }^{t+d t} \Delta \varepsilon\right]_{\left\{g^{* i} \otimes g^{* j}\right\}}=\left[U_{\mathrm{n}}\right]_{\left\{e_{i}^{*} \otimes g_{j}^{*}\right\}}^{\top} \cdot\left[{ }^{t+d t} \Delta \varepsilon\right]_{\left\{e_{i}^{*} \otimes e_{j}^{*}\right\}} \cdot\left[U_{\mathrm{n}}\right]_{\left\{e_{i}^{*} \otimes g_{j}^{*}\right\}} \cdot$

To account for the viscoelastic bending behaviour, the incremental viscous Cauchy stress $\Delta \sigma^{\mathrm{v}}$ is added to the incremental elastic Cauchy stress $\Delta \sigma^{\mathrm{e}}$ within the fibre-parallel frame, which yields the total stress at the end of the increment

$\left[{ }^{t+d t} \sigma^{\mathrm{vk}}\right]_{\left\{g_{i}^{*} \otimes g_{j}^{*}\right\}}=\left[{ }^{t} \sigma^{\mathrm{vk}}+^{t+d t} \Delta \sigma^{\mathrm{e}}+^{t+d t} \Delta \sigma^{\mathrm{v}}\right]_{\left\{g_{i}^{*} \otimes g_{j}^{*}\right\}}$.

The index 'vk' represents the applied visco-elastic Voigt-Kelvin approach. The incremental viscous Cauchy stress $\Delta \sigma^{\mathrm{v}}=\left[{ }^{t+d t} \sigma^{\mathrm{v}}\right]_{\left.g_{i}^{*} \otimes g_{j}^{*}\right\}}-\left[{ }^{t} \sigma^{\mathrm{v}}\right]_{\left\{g_{i}^{*} \otimes g_{j}^{*}\right\}}$ is determined via

$\left[{ }^{t+d t} \sigma^{\mathrm{v}}\right]_{\left\{g_{i}^{*} \otimes g_{j}^{*}\right\}}=2 \eta_{\mathrm{D}}\left(\dot{\gamma}_{\mathrm{eq}}\right)[\square]\left\{g_{i}^{*} \otimes g_{j}^{*} \otimes g_{k}^{*} \otimes g_{l}^{*}\right\}:\left[{ }^{t+d t} \boldsymbol{D}\right]_{\left\{g^{* k} \otimes \mathbf{g}^{*}\right\}}$,

where $\boldsymbol{D}$ is the rate of deformation tensor, I fourth order identity tensor and $\eta_{\mathrm{D}}\left(\dot{\gamma}_{\text {eq }}\right)$ the non-linear viscosity depending on a equivalent of the deformation rate $\dot{\gamma}_{\text {eq }}=\sqrt{\boldsymbol{D}: \boldsymbol{D}}$, which is obtained by the Frobenius norm. Finally, the section moment $\left[{ }^{t+d t} \boldsymbol{M}\right]$ within the fibre-parallel frame is determined by the total moment $\left[{ }^{t} \boldsymbol{M}\right]$ and the numeric integration of the incremental stress over the initial thickness $t_{0}$ of the shell element

$\left.\left.{ }^{t+d t} \boldsymbol{M}\right]_{\left\{g_{i}^{*} \otimes g_{j}^{*}\right\}}=\left[{ }^{t} \boldsymbol{M}\right]_{\left\{g_{i}^{*} \otimes g_{j}^{*}\right\}}+\int_{t_{0}}\left({ }^{t+d t}\left[\Delta \sigma^{\mathrm{e}}+\Delta \sigma^{\mathrm{v}}\right] \mathbf{g}_{i}^{*} \otimes g_{j}^{*}\right\}\right) \bar{f}_{33}^{2} z d z$,

where $\bar{f}_{33}$ is the deformation gradient in thickness direction which results from the assumption of material incompressibility. The bending moments are returned to the solver after being transformed to the Green-Naghdi's frame. Section forces are neglected $(\boldsymbol{N}=0)$ to suppress the membrane part within the shell element.

To account for the infiltrated bending behaviour, a nonlinear elasticity $E\left(\dot{\gamma}_{\text {eq }}\right)$ and a nonlinear viscosity $\eta_{\mathrm{D}}\left(\dot{\gamma}_{\mathrm{eq}}\right)$ are implemented with the rheometer according to

$E\left(\dot{\gamma}_{\mathrm{eq}}\right)=\frac{E_{0}-E_{\infty}}{1+m_{1} \dot{\gamma}_{\mathrm{eq}}^{1-n_{1}}}+E_{\infty} \quad$ and $\quad \eta_{D}\left(\dot{\gamma}_{\mathrm{eq}}\right)=\frac{\eta_{0}-\eta_{\infty}}{1+m_{2} \dot{\gamma}_{\mathrm{eq}}^{1-n_{2}}}+\eta_{\infty}$,

by means of formulations based on isotropic Cross model [45], where mechanical properties depend on the introduced rate equivalent $\dot{\gamma}_{\mathrm{eq}}$.

\subsection{Determination material parameters}

The experimental results of cantilever test and RBT are used to parametrise two bending models, henceforth called cantilever and rheometer model. Both approaches are parametrised separately using inverse FEA-based material parameter extraction. An implicit integration scheme in conjunction with finite strain shell elements (S4R) is used for the FE-models of both tests. An in-house python-based optimisation loop is applied to identify suitable material parameters for both bending models.

For the parametrisation of the cantilever bending model, the above outlined modelling approach is reduced to a purely hypoelastic approach $\left(\eta_{D} \rightarrow 0\right)$ using constant elasticity moduli $E_{i}^{\text {can }}$, that are determined for each viscosity according to Table 5 . The bending length is used as the optimisation goal.

Table 5

Material parameter of the cantilever model.

\begin{tabular}{ccccc}
\hline & dry & $20 \mathrm{mPas}$ & $135 \mathrm{mPas}$ & $250 \mathrm{mPas}$ \\
\hline$E_{i}^{\mathrm{can}} / \mathrm{MPa}$ & 788.49 & 418.05 & 477.84 & 526.58 \\
\hline
\end{tabular}

(a) dry

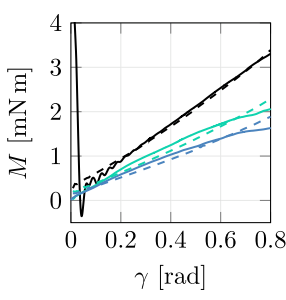

(b) $250 \mathrm{mPas}$

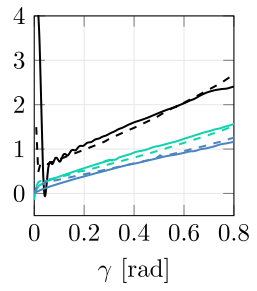

(c) $20 \mathrm{mPas}$

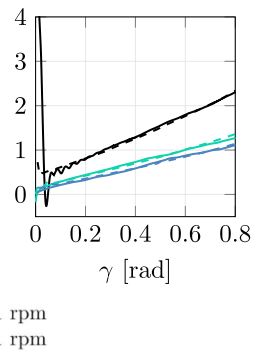

Fig. 11. Parametrisation results of the rheometer model for three viscosities at different deflection rates. (For interpretation of the references to color in this figure legend, the reader is referred to the web version of this article.) (a)

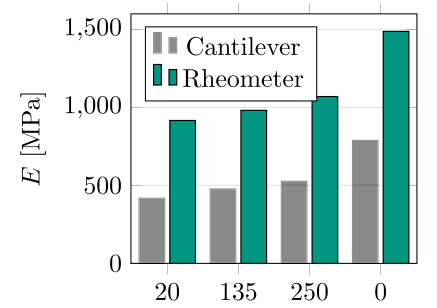

(b)

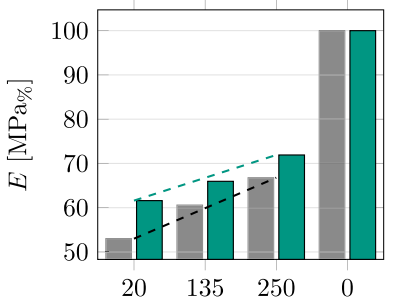

Fig. 12. Comparison of the parametrisation results in terms of the elasticity moduli for different viscosities (mPas) at corresponding rates; (a) absolute, (b) relative, related to dry reference. (For interpretation of the references to color in this figure legend, the reader is referred to the web version of this article.)

Regarding the parametrisation of the rheometer bending model, a simulation set-up similar to [7] is applied at the corresponding deflection rates $\left(\dot{\gamma}_{i}=0.1,1,10 \mathrm{rpm}\right)$ with the above outlined hyperviscoelastic bending model. The parametrisation results (see Table 8 Appendix A) shown in Fig. 11 are in good agreement with the experimental ones.

A comparison of the identified absolute and relative elasticity moduli of both models is presented in Fig. 12 at corresponding rates. The absolute values reflect the systematic differences that were obtained during the comparison of the experimentally determined bending stiffnesses (cf. Fig. 9 (a)). Moreover, the relative comparison shows that the identified elasticity values of the cantilever model decrease faster than the ones for of rheometer model (cf. Fig. 12 (b)). This is reasonable, since no rate-dependency is modelled in the cantilever model. Thus, the identification of material parameters provide a consistent representation of the experimental results.

The presented model should be considered as a straightforward approach, which is suitable to account for the rate- and viscosity-dependent bending behaviour but involves some noteworthy limitations. The hypoviscoelastic formulation implies a path-dependency that can affect the results for mainly non-monotonous bending deformations, due to the non-linearity of the elastic part of the constitutive equation. Therefore, a geometry without a global blank holder is used to apply a mostly monotonous bending deformation on the fabrics. Furthermore, the model is not suitable to account for warpage or springback effects in the presented form. Thus, obtained results are only reliable until the tool is closed completely.

\subsection{Sensitivity analysis by means of forming simulation}

The outlined modelling approach, along with the two parametrised bending models, is used to evaluate the influence of infiltration-dependent bending behaviour and their characterisation approach on part level. As outlined in Table 6, several forming simulation are performed in ABAQUS with an explicit time integration scheme. 
Table 6

Outline of the simulation setups.

\begin{tabular}{ccccc}
\hline Sim. Ref. & Layup $\left[^{\circ}\right]$ & Viscosity [mPas] & Bend. model & Contact settings \\
\hline 1 & {$[0 / 90]$} & $0 \& 20$ & Rheometer & TP only \\
2 & {$[ \pm 45]$} & $0 \& 20$ & Rheometer & TP only \\
3 & {$[0 / 90]$} & $0 \& 20$ & Cantilever & TP only \\
4 & {$[ \pm 45]$} & $0 \& 20$ & Cantilever & TP only \\
& & & & \\
5 & {$[0 / 90, \pm 45]$} & $0 \& 20$ & Rheometer & TP + PP low \\
6 & {$[0 / 90, \pm 45]$} & $0 \& 20$ & Cantilever & TP + PP low \\
7 & {$[0 / 90, \pm 45]$} & $0 \& 20$ & Rheometer & TP + PP high \\
8 & {$[0 / 90, \pm 45]$} & $0 \& 20$ & Cantilever & TP + PP high \\
\hline
\end{tabular}

The dry specimens and the ones infiltrated with $20 \mathrm{mPas}$ provide the extreme values of the experimentally obtained bending stiffnesses (see. Fig. 12). Therefore, only results using these two viscosities are presented subsequently. The tools are modelled as discrete rigid surfaces and the applied tool stroke is implemented via a displacement boundary condition, as illustrated in Fig. 13(a). The tool geometry is adapted from [30], an the tool is closed within $2 \mathrm{~s}$ at a constant velocity $u_{\text {Tool }}=25.5 \mathrm{~mm} / \mathrm{s}$. Furthermore, a constant gravity load is applied to the model. Each ply, with a constant thickness of $0.3 \mathrm{~mm}$, is modelled by means of 70,756 triangular elements. Preliminary studies showed, that the occurring curvature rates during forming are in good agreement with the assumed and thus the parametrised range, as the histogram in Fig. 13 (b) demonstrates. In the following, the modified mean curvature values $\bar{\kappa}_{\mathrm{MM}}^{\mathrm{el}}$, subsequently referred to as 'curvature' and introduced by Haanappel [46], is used to evaluate and quantify the predicted curvatures in specific areas by a single scalar value. The presented curvature values are always calculated with respect to the final tool shape. Since the results of the $\pm 45^{\circ}$ and $0 / 90^{\circ}$ simulation setups are identical, only the $\pm 45^{\circ}$ results are presented subsequently.

\subsection{Numerical results}

A comparison between the predicted curvatures of the $\pm 45^{\circ}$ single ply simulation setups 2 and 4 is presented in Fig. 14. The presented results correspond to a remaining tool cavity of $10 \mathrm{~mm}$. Within each bending model $(a, b)$, the overall shape and predicted curvatures are quite similar for two viscosities. The curvatures within the tool shape only slightly increase with infiltration. In contrast to the rheometer results, the predicted curvatures of the cantilever model, inside and outside the tool shape, are increased and the differences between the results using the two viscosities are slightly more pronounced. The most noticeable difference between the two models ( $a$ and $b$ ) is the predicted sag outside the tool shape.

The numerical results of the two ply setups are illustrated in Fig. 15. The presented results are subdivided according to the applied ply-ply contact settings $(\mathrm{a}-$ low, $\mathrm{b}-$ high). Almost identical results are obtained for both models when the low contact is applied (a), compared to the single ply results (cf. Fig. 14). Consequently, similar tendencies, curvatures relations and shapes are obtained. In contrast to the former, distinctive winkling is predicted when relative slip is prevented (cf. Fig. 15 (b)). The predicted curvature values are therefore signifiant higher. Still, the same tendencies in terms of viscosity impact and bending model apply. The impact of viscosity is rather low and more pronounced when the cantilever model is used. Furthermore, the cantilever bending model predicts significantly higher curvature values than the rheometer model. Position and shape of individual wrinkles vary in all configurations when relative slip is prevented within the contact formulation.

\subsection{Discussion of the numerical results}

The numerical results of the single-ply simulation setups (Sim. Ref. 1-4) match the results of the two-ply simulation setups with low contact interaction (Sim Ref. 5 and 6), because a mostly unconstrained deformation of the single plies is possible in all these simulations. The obtained results directly relate to the applied bending models and their corresponding material parameters. The lower the bending stiffness, the higher the sag and predicted curvatures (cf. Fig. 14b) and Fig. 15(a)). Recalling the identified material parameters in Fig. 12, the bending stiffness decreases along with decreasing infiltration viscosity and the values obtained by the rheometer bending test are approximately $20-50 \%$ higher than the infiltration-corresponding values of the cantilever test for curvature rates below $\dot{\kappa}=6.7( \pm 2.2) / 10^{-4} \cdot \mathrm{mms}^{-1}$. Consequently, the cantilever model predicts higher curvatures and more sag than the rheometer model throughout all the numerical results.

The above outlined reasoning also applies for the two-ply simulation setups containing the high contact interaction (Sim Ref. 7 and 8). However, the suppressed relative slip between the plies leads to increased in-plane forces as a consequence of constrained deformation and therefore to the formation of wrinkles as visualised in Fig. 15 (b). According to Dörr et al. [7] the initial bending stiffness determines the (a)

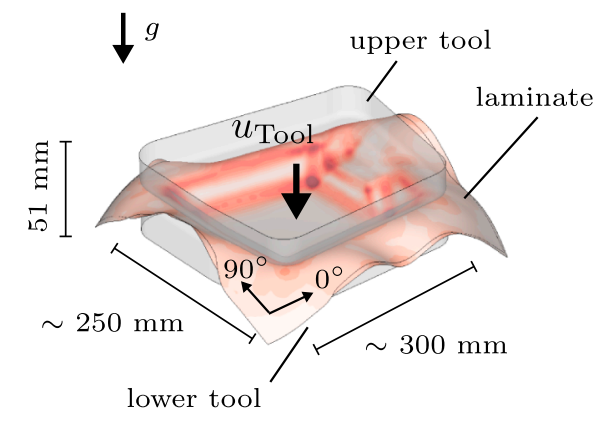

Ply size: $400 \times 400 \mathrm{~mm}$ (b)

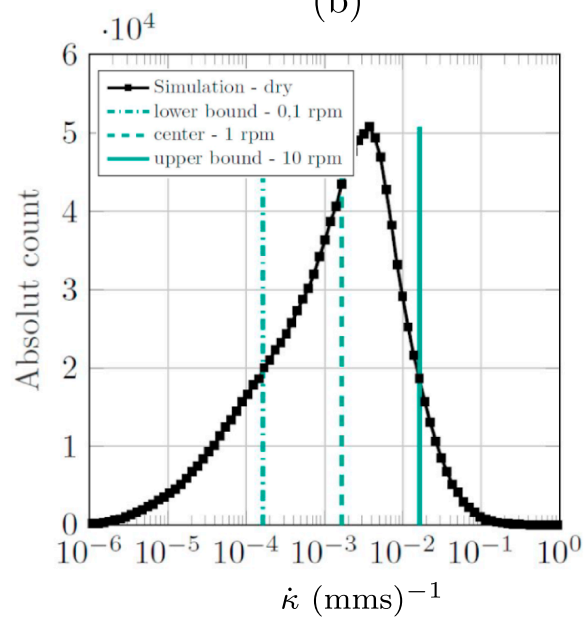

Fig. 13. (a) Illustration of FE forming simulation setup 5 in ABAQUs; (b) Histogram of the occurring curvature rates $\dot{\kappa}$ during forming simulation of the generic geometry - dry parameters provide the highest rates; Parametrised range indicated by vertical lines. (For interpretation of the references to color in this figure legend, the reader is referred to the web version of this article.) 


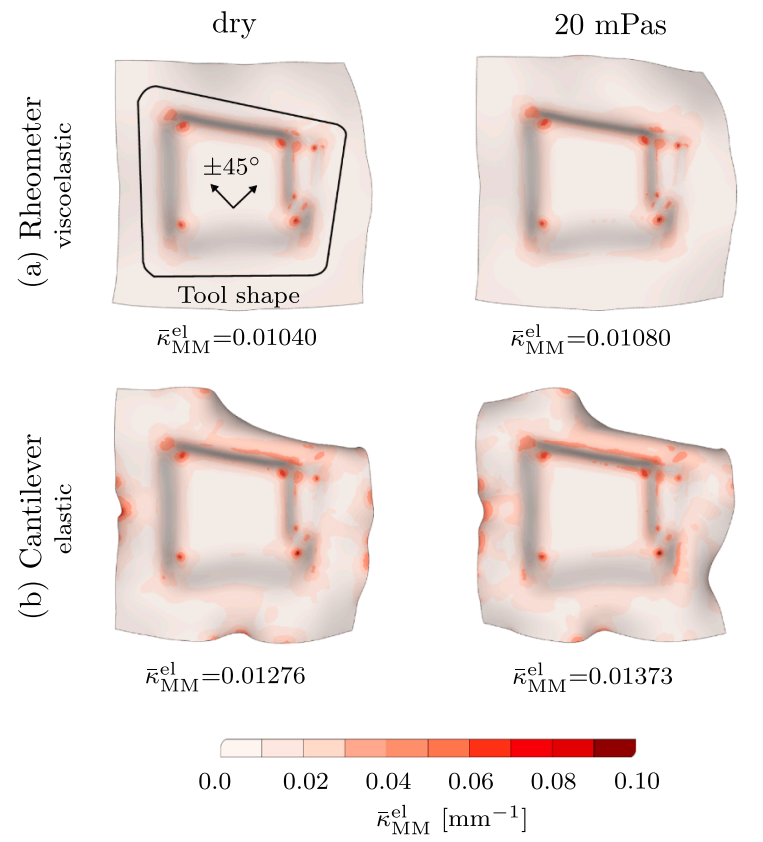

Fig. 14. Curvatures $\bar{\kappa}_{\mathrm{MM}}^{\mathrm{el}}$ predicted by both bending models for a remaining tool cavity of $10 \mathrm{~mm}$ and two viscosities (dry and $20 \mathrm{mPas}$ ) according to the $\pm 45^{\circ}$ simulation setups 2 and 4.; curvature values beneath the pictures correspond to the outlined tool shape. (For interpretation of the references to color in this figure legend, the reader is referred to the web version of this article.)

onset of wrinkles, whereas rate-dependencies determine their progression. Since the initial bending stiffness of the rheometer model is higher compared to the cantilever model, less wrinkling is predicted, which is also reflected by the averaged curvature values of the tool shape (cf. Fig. 15 (b)). Although the predicted averaged curvatures $\bar{\kappa}_{\text {MM }}^{\mathrm{el}}$ only increase slightly with infiltration for both bending models, the position and shape of the wrinkles differ between every configuration, at least in certain areas of the part. This is contributed to the fact that wrinkling is an instability issue, governed by the ratio of in- and out-of-plane stresses. In situations with increased in-plane stresses, the model responds more sensitively to viscosity-dependent changes of the bending stiffness. Consequently, differences between the shape and size of the predicted wrinkles are noticeable within the high contact simulations.

In addition, it has to be considered that, although the kinetic energies are very low compared to the total energies in the model $(<2 \%)$, some degree of oscillation cannot be prevented when using a solely elastic bending model (cantilever). This may cause differences of the plies' outer shape, especially for the single plies (cf. Fig. 14). Regarding the rheometer model, the viscous part damps such oscillations.

Collectively, the numerical results reveal that the bending models (RBT, Cantilever), lead to differences in shape, predicted curvatures and, in case of strong contact interaction, position and shape of winkles on part level. The usage of a viscoelastic bending model is recommended as the material behaviour is shown to be rate-dependent, even for the dry specimens. Furthermore, the results emphasise the relevance of an accurate characterisation of initial bending stiffness, which is not so straightforward, as shown in Section 2.3. In general, the relevance of a viscosity-dependent bending model is shown to be of minor importance within the WCM process, compared to e.g. the thermoforming of thermoplastic UD-Tapes [7,29,47]. This is mostly because relative slippage between the plies prevents most critical situations in WCM. Thus, localised stresses tend to be released by relative inter-ply slip and not by bending. Moreover, the process relevant viscosity range (20-250 mPas) is much lower than within for example the thermoforming of thermoplastic UD-Tapes or pregregs.
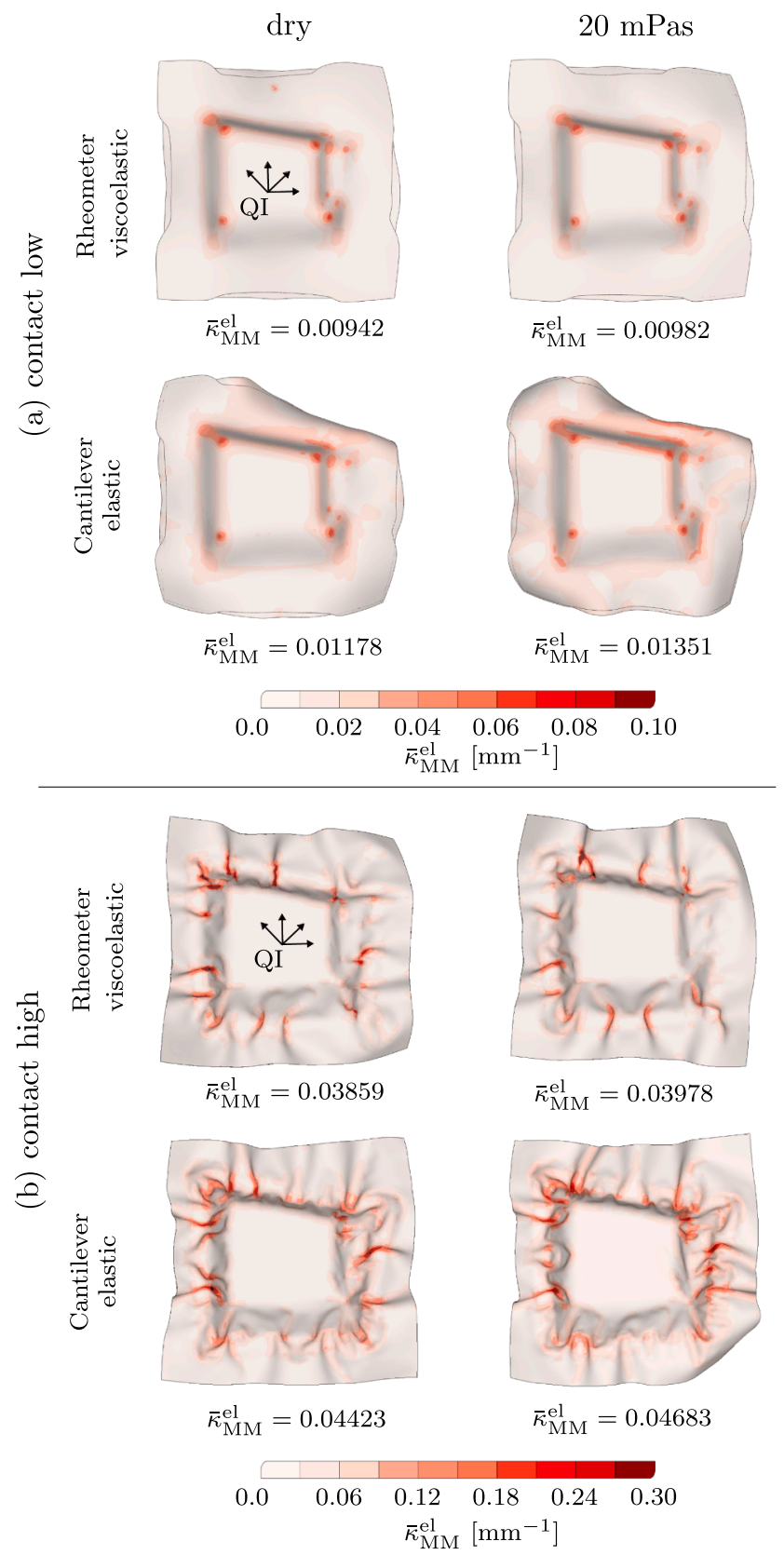

Fig. 15. Comparison of the numerical results and predicted curvatures $\bar{\kappa}_{\mathrm{MM}}^{\mathrm{el}}$ within the two-ply simulations (Sim. Ref. 5-8) for a remaining tool cavity of $10 \mathrm{~mm}$; (a) low, (b) high contact settings; curvature values beneath the pictures correspond to the tool shape. (For interpretation of the references to color in this figure legend, the reader is referred to the web version of this article.)

\section{Conclusion}

A slightly modified cantilever test and a rheometer bending test are applied to investigate and characterise the bending behaviour of dry and low viscous infiltrated woven fabrics. Experimental results reveal rateand viscosity-dependent material response, which is attributed to a combination of contact interface wetting (lubrication) and coating of the fibres. The rate-dependent bending behaviour of dry fabric could be particularly interesting for preforming simulations within the context of RTM. Moreover, infiltration leads rate- and viscosity-dependent hysteresis bending behaviour. The origin for the observed material behaviour is discussed and in agreement with existing literature $[10,14,19,20,48]$.

Beyond that, Cantilever test and RBT are directly compared for the first time, which revealed a qualitative, but not quantitative 
comparability. Based on existing literature, three reasons are outlined and discussed to explain the systematic deviation between the experimental results. The RBT invokes superimposed friction at the contact interfaces $[6,27,46]$, whereas the specimens in the cantilever test are exposed to undetermined compaction [14]. The latter should receive special attention, since it significantly influences the determined material parameter and is not systematically reported in literature yet. Still, the question, which bending test is closer to reality and provides more reliable material parameters cannot be answered entirely on the basis of only one investigated material. Therefore, a deeper investigation of the test boundary conditions and a more extensive benchmark study of different types of textile material would be interesting for future research. On the base of this reasoning, it could be very interesting, if the same deviations between the two tests can be reproduced for other material systems with higher viscous matrices.

Furthermore, both approaches are evaluated in terms of their practical suitability to measure infiltrated bending behaviour. While the cantilever approach should only be used when a fast assessment of the dry and infiltrated elastic material parameters is required, the rheometer approach is generally more recommendable, because it is able to captures more accurate data and enables determination of the ratedependent, plasticity and hysteresis material bending behaviour.

Finally, the experimental results of Cantilever test and RBT are used to parametrise two corresponding FE-based bending models. Evaluation of the numerical results reveal an effect of the applied infiltration-dependent bending models on part level. Moreover, the relevance depends not only on the bending model, but also on other process conditions, as for instance the applied contact behaviour. Thus, an accurate contact model is required to account for the strong dependence between contact and bending behaviour, as Haanappel et al. $[27,46]$, among others, already pointed out regarding prepregs and thermoplastic UD-Tapes. To account for the ratedepending material bending behaviour, the usage of a viscoelastic bending model is recommended. Still, the viscosity-dependency of this applied viscoelastic bending model mainly matters in critical process situations.
Thus, the general importance of a viscosity-dependent bending model is expected to be of minor importance within process simulation models of the WCM process. This differs from the thermoforming process of thermoplastic UD-Tapes and Prepregs, where viscosity-dependent bending characterisation and modelling is strongly recommended [7,10,29,49].

Possible expansions of the presented bending model could focus on more detailed investigation and modelling of the hitherto neglected plasticity and hysteresis behaviour. This could provide additional knowledge and a deeper material comprehension, similar to the inplane approaches presented by Denis et al. [50] for dissipative constitutive models. Regarding thicker materials, suitable modelling approaches should account for transversal shear, for instance by using a second gradient approach [51].

Future work will focus on further identification and modelling of mutual dependencies within the viscous draping stage including a proper infiltration-dependent contact formulation. Furthermore, numerical results on part level will be compared to experimental draping tests. The prediction of simultaneous fluid propagation along with infiltration-dependent material models during draping remains a major objective of future research to enable a physics-based process simulation modelling of the wet compression moulding process.

\section{Declaration of Competing Interest}

The authors declare no conflict of interest.

\section{Acknowledgment}

The authors would like to thank the German State Ministry for Science, Research and Art of Baden-Württemberg (MWK) for the funding of the project Forschungsbrücke Karlsruhe-Stuttgart (Gn. 32-7533-4$110 / 10 / 3,4$ ) for which the presented work is carried out. The work is also part of the Young Investigator Group (YIG) "Tailored Composite Materials for Lightweight Vehicles", funded by the Vector Stiftung.

Appendix A. Material parameters

Table 7

Ply-ply contact parameter sets.

\begin{tabular}{lccc}
\hline & $\mu^{\mathrm{Ply}}[-]$ & $\eta^{\mathrm{Ply}}[\mathrm{Ns} / \mathrm{mm}]$ & $\tau_{0}^{\mathrm{Ply}}[\mathrm{N}]$ \\
\hline low & 0.28 & 0.0 & $2.5 * 10^{-5}$ \\
high & 0.28 & 0.0 & $2.5 * 10^{-2}$ \\
\hline
\end{tabular}

Table 8

Material parameter of the rheometer models.

\begin{tabular}{|c|c|c|c|c|}
\hline \multirow{2}{*}{$\begin{array}{l}\text { Viscosity } \\
\eta / \mathrm{mPas}\end{array}$} & \multicolumn{4}{|c|}{ Parameter for $E_{i}^{\text {rheo }}$} \\
\hline & $E_{0} / \mathrm{MPa}$ & $E_{\infty} / \mathrm{MPa}$ & $m_{1}$ & $n_{1}$ \\
\hline dry & 987.079 & 3381.037 & 72.917 & 0.299 \\
\hline 20 & 628.903 & 1980.352 & 77.302 & 0.252 \\
\hline 135 & 645.101 & 2161.137 & 76.402 & 0.248 \\
\hline 250 & 669.672 & 2278.262 & 62.484 & 0.283 \\
\hline Viscosity & \multicolumn{4}{|c|}{ Parameter for $\eta_{D}$} \\
\hline$\eta / \mathrm{mPas}$ & $\eta_{0} / \mathrm{MPas}$ & $\eta_{\infty} / \mathrm{MPas}$ & $m_{2}$ & $n_{2}$ \\
\hline dry & 45301.348 & 5.410 & 248515.843 & -0.0001 \\
\hline 20 & 39127.217 & 172.315 & 474982.425 & -0.007 \\
\hline 135 & 42021.124 & 207.418 & 351671.347 & -0.016 \\
\hline 250 & 42932.570 & 210.495 & 401156.578 & -0.025 \\
\hline
\end{tabular}




\section{References}

[1] Bergmann J, Dörmann H, Lange R. Interpreting process data of wet pressing process. Part 2: verification with real values. J Compos Mater 2016;50(17):2409-19. https://doi.org/10.1177/0021998315604038.

[2] Poppe C, Dörr D, Henning F, Kärger L. A 2d modeling approach for fluid propagation during fe-forming simulation of continuously reinforced composites in wet compression moulding. AIP Conf Proc 2018:020022. https://doi.org/10.1063/1.5034823.

[3] Bockelmann P. Process control in compression molding of composites: dissertation. Fakultät für Maschinenwesen, Technische Universität München; 2017.

[4] Bergmann J, Dörmann H, Lange R. Interpreting process data of wet pressing process. Part 1: theoretical approach. J Compos Mater 2016;50(17):2399-407. https://doi. org/10.1177/0021998315604728.

[5] Poppe C, Dörr D, Henning F, Kärger L. Experimental and numerical investigation of the shear behaviour of infiltrated woven fabrics. Compos Part A: Appl Sci Manuf https://doi.org/10.1016/j.compositesa.2018.08.018.

[6] Sachs U. Friction and bending in thermoplastic composites forming processes. Enschede: University of Twente; 2014.

[7] Dörr D, Schirmaier FJ, Henning F, Kärger L. A viscoelastic approach for modeling bending behavior in finite element forming simulation of continuously fiber reinforced composites. Compos Part A: Appl Sci Manuf 2017;94:113-23. https://doi. org/10.1016/j.compositesa.2016.11.027.

[8] Peirce FT. 26-the "handle" of cloth as a measurable quantity. J Textile Inst Trans 1930;21(9):377-416. https://doi.org/10.1080/19447023008661529.

[9] DIN-53362. Bestimmung der Biegesteifigkeit Verfahren nach Cantilever; 2003.

[10] Boisse P, Colmars J, Hamila N, Naouar N, Steer Q. Bending and wrinkling of composite fiber preforms and prepregs. a review and new developments in the draping simulations. Compos Part B: Eng https://doi.org/10.1016/j.compositesb 2017.12.061.

[11] de Bilbao E, Soulat D, Hivet G, Launay J, Gasser A. Bending test of composite reinforcements. Int J Mater Form 2008:835-8. https://doi.org/10.1007/s12289-0080265-z.

[12] Thoma B. Methodische Umsetzung und Bewertung eines neuartigen Prozesses zur lokalen und automatisierten Fixierung von textilen Preformlingen: Dissertation, vol. Band 62 of Wissenschaftliche Schriftenreihe des Fraunhofer ICT. Stuttgart: Fraunhofer Verlag; 2015

[13] Schirmaier FJ, Weidenmann KA, Kärger L, Henning F. Characterisation of the draping behaviour of unidirectional non-crimp fabrics (UD-NCF). Compos Part A: Appl Sci Manuf 2016;80:28-38. https://doi.org/10.1016/j.compositesa.2015.10.004.

[14] de Bilbao E, Soulat D, Hivet G, Gasser A. Experimental study of bending behaviour of reinforcements. Exp Mech 2010;50(3):333-51. https://doi.org/10.1007/s11340009-9234-9.

[15] Liang B, Hamila N, Peillon M, Boisse P. Analysis of thermoplastic prepreg bending stiffness during manufacturing and of its influence on wrinkling simulations. Compos Part A: Appl Sci Manuf 2014;67:111-22. https://doi.org/10.1016/j. compositesa.2014.08.020.

[16] Liang B, Chaudet P, Boisse P. Curvature determination in the bending test of continuous fibre reinforcements. Strain 2016;53(1):111-22. https://doi.org/10.1111/ str.12213.

[17] Dangora LM, Mitchell CJ, Sherwood JA. Predictive model for the detection of outof-plane defects formed during textile-composite manufacture. Compos Part A: Appl Sci Manuf 2015;78:102-12. https://doi.org/10.1016/j.compositesa.2015.07.011.

[18] Kawabata S. The standardization and analysis of hand evaluation. 2nd ed. Osaka: Textile Machinery Society of Japan; 1980.

[19] Lahey TJ. Modelling hysteresis in the bending of fabrics Ph.D. thesis Ontario, Canada: Waterloo; 2002

[20] Lomov S, Verpoest I, Barburski M, Laperre J. Carbon composites based on multiaxial multiply stitched preforms. Part 2 . KES-F characterisation of the deformability of the preforms at low loads. Compos Part A: Appl Sci Manuf 2003;34(4):359-70. https://doi.org/10.1016/S1359-835X(03)00025-3.

[21] Dahl PR. Solid friction damping of mechanical vibrations. AIAA J 1976;14(12):1675-82. https://doi.org/10.2514/3.61511.

[22] Grosberg P. The mechanical properties of woven fabrics part ii: the bending of woven fabrics. Text Res J 1966;36(3). https://doi.org/10.1177/004051756603600301.

[23] Margossian A, Bel S, Hinterhoelzl R. Bending characterisation of a molten unidirectional carbon fibre reinforced thermoplastic composite using a dynamic mechanical analysis system. Compos Part A: Appl Sci Manuf 2016;77:154-63. https:// doi.org/10.1016/j.compositesa.2015.06.015.

[24] Sun F, Chen C, Liu S, Jin H, He L, Zhaoqun Du, et al. Simulative analysis of the bending property of woven fabric by the comprehensive handle evaluation system for fabrics and yarns. Text Res J 2016;87(16):1977-90.

[25] Cao J, Akkerman R, et al. Characterization of mechanical behavior of woven fabrics: experimental methods and benchmark results. Compos Part A: Appl Sci Manuf 2008;39(6):1037-53. https://doi.org/10.1016/j.compositesa.2008.02.016.

[26] Sachs U, Akkerman R, Fetfatsidis K, Vidal-Sallé E, Schumacher J, Ziegmann G, et al. Characterization of the dynamic friction of woven fabrics: experimental methods and benchmark results. Compos Part A: Appl Sci Manuf 2014;67:289-98. https:// doi.org/10.1016/j.compositesa.2014.08.026.

[27] Haanappel SP, ten Thije R, Sachs U, Rietman B, Akkerman R. Formability analyses of uni-directional and textile reinforced thermoplastics. Compos Part A: Appl Sci Manuf 2014;56:80-92. https://doi.org/10.1016/j.compositesa.2013.09.009.

[28] Guzman-Maldonado E, Hamila N, Boisse P, Bikard J. Thermomechanical analysis, modelling and simulation of the forming of pre-impregnated thermoplastics composites. Compos Part A: Appl Sci Manuf 2015;78:211-22. https://doi.org/10.1016/ j.compositesa.2015.08.017

[29] Dörr D, Henning F, Kärger L. Nonlinear hyperviscoelastic modelling of intra-ply deformation behaviour in finite element forming simulation of continuously fibrereinforced thermoplastics. Compos Part A: Appl Sci Manuf 2018;109:585-96. https://doi.org/10.1016/j.compositesa.2018.03.037.

[30] Dörr D, Joppich T, Schirmaier F, Mosthaf T, Kärger L, Henning F. A method for validation of finite element forming simulation on basis of a pointwise comparison of distance and curvature. AIP Conf Proc 2016:170011. https://doi.org/10.1063/1. 4963567.

[31] Boisse P, Hamila N, Madeo A. The difficulties in modeling the mechanical behavior of textile composite reinforcements with standard continuum mechanics of cauchy. some possible remedies. Int J Solids and Struct https://doi.org/10.1016/j.ijsolstr. 2016.12.019.

[32] Hamila N, Boisse P. Locking in simulation of composite reinforcement deformations. analysis and treatment. Compos Part A: Appl Sci Manuf 2013;53:109-17. https://doi.org/10.1016/j.compositesa.2013.06.001.

[33] Schirmaier FJ, Dörr D, Henning F, Kärger L. A macroscopic approach to simulate the forming behaviour of stitched unidirectional non-crimp fabrics (ud-ncf). Compos Part A: Appl Sci Manuf 2017;102:322-35. https://doi.org/10.1016/j. compositesa.2017.08.009.

[34] Harrison P, Yu W-R, Long AC. Rate dependent modelling of the forming behaviour of viscous textile composites. Compos Part A: Appl Sci Manuf 2011;42(11):1719-26. https://doi.org/10.1016/j.compositesa.2011.07.026.

[35] Allaoui S, Boisse P, Chatel S, Hamila N, Hivet G, Soulat D, et al. Experimental and numerical analyses of textile reinforcement forming of a tetrahedral shape. Compos Part A: Appl Sci Manuf 2011;42(6):612-22. https://doi.org/10.1016/j.compositesa. 2011.02.001.

[36] Guzman-Maldonado E, Hamila N, Naouar N, Moulin G, Boisse P. Simulation of thermoplastic prepreg thermoforming based on a visco-hyperelastic model and a thermal homogenization. Mater Des 2016;93:431-42. https://doi.org/10.1016/j. matdes.2015.12.166.

[37] Dörr D, Schirmaier FJ, Henning F, Kärger L. On the relevance of modeling viscoelastic bending behavior in finite element forming simulation of continuously fiber reinforced thermoplastics. AIP Conf Proc 2017:030003. https://doi.org/10.1063/1.5007990.

[38] Boisse P, Naouar N, Charmetant A. Finite element analysis of composite forming at macroscopic and mesoscopic scale. In: Boisse P, editor. Advances in composites manufacturing and process design, Woodhead publishing series in composites science and engineering Cambridge, UK: Woodhead Publishing; 2015. p. 297-315. https://doi.org/10.1016/B978-1-78242-307-2.00014-2.

[39] Bussetta P, Correia N. Numerical forming of continuous fibre reinforced composite material: a review. Compos Part A: Appl Sci Manuf 2018;113:12-31. https://doi. org/10.1016/j.compositesa.2018.07.010.

[40] Sachs U, Akkerman R. Viscoelastic bending model for continuous fiber-reinforced thermoplastic composites in melt. Compos Part A: Appl Sci Manuf 2017;100:333-41. https://doi.org/10.1016/j.compositesa.2017.05.032.

[41] Li L, Zhao Y, Vuong H-G-N, Chen Y, Yang J, Duan Y. In-plane shear investigation of biaxial carbon non-crimp fabrics with experimental tests and finite element modeling. Mater Des 2014;63:757-65. https://doi.org/10.1016/j.matdes.2014.07.007.

[42] Tourlonias M, Bueno M-A, Poquillon D. Friction of carbon tows and fine single fibres. Compos Part A: Appl Sci Manuf 2017;98:116-23. https://doi.org/10.1016/j. compositesa.2017.03.017.

[43] Dörr D, Faisst M, Joppich T, Poppe C, Henning F, Kärger L. Modelling approach for anisotropic inter-ply slippage in finite element forming simulation of thermoplastic ud-tapes. AIP Conf Proc 2018:020005. https://doi.org/10.1063/1.5034806.

[44] Poppe C, Dörr D, Fabian K, Kärger L. Experimental and numerical investigation of the contact behavior of continuously reinforced composites in wet compression molding. AIP conference proceedings to 22nd international conference on material forming. 2019.

[45] Macosko CW. Rheology: principles, measurements, and applications. Advances in interfacial engineering series. New York: VCH; 1994.

[46] Haanappel S. Forming of UD fibre reinforced thermoplastics: a critical evaluation of intra-ply shear; 2013. https://doi.org/10.3990/1.9789036535014.

[47] ten Thije R, Akkerman R. A multi-layer triangular membrane finite element for the forming simulation of laminated composites. Compos Part A: Appl Sci Manuf 2009;40(6-7):739-53. https://doi.org/10.1016/j.compositesa.2009.03.004.

[48] Tourlonias M, Bueno M-A. Experimental simulation of friction and wear of carbon yarns during the weaving process. Compos Part A: Appl Sci Manuf 2016;80:228-36. https://doi.org/10.1016/j.compositesa.2015.07.024.

[49] Ropers S, Kardos M, Osswald TA. A thermo-viscoelastic approach for the characterization and modeling of the bending behavior of thermoplastic composites. Compos Part A: Appl Sci Manuf 2016;90:22-32. https://doi.org/10.1016/j. compositesa.2016.06.016.

[50] Denis Y, Guzman-Maldonado E, Hamila N, Colmars J, Morestin F. A dissipative constitutive model for woven composite fabric under large strain. Compos Part A: Appl Sci Manuf 2018;105:165-79. https://doi.org/10.1016/j.compositesa.2017.11. 018.

[51] Boisse P, Bai R, Colmars J, Hamila N, Liang B, Madeo A. The need to use generalized continuum mechanics to model 3d textile composite forming. Appl Compos Mater 2018;25:761-71. https://doi.org/10.1007/s10443-018-9719-8. 
Karlsruher Institut für Technologie

\section{Repository KITopen}

Dies ist ein Postprint/begutachtetes Manuskript.

Empfohlene Zitierung:

Poppe, C.; Rosenkranz, T.; Dörr, D.; Kärger, L.

Comparative experimental and numerical analysis of bending behaviour of dry and low viscous infiltrated woven fabrics.

2019. Composites / A, 124

doi:10.5445/IR/1000096213

Zitierung der Originalveröffentlichung:

Poppe, C.; Rosenkranz, T.; Dörr, D.; Kärger, L.

Comparative experimental and numerical analysis of bending behaviour of dry and low viscous infiltrated woven fabrics.

2019. Composites / A, 124, Art. Nr.: 105466

doi:10.1016/j.compositesa.2019.05.034

Lizenzinformationen: CC BY-NC-ND 4.0 